\title{
Hermanos y cofrades en la aljama de Toledo a principios del siglo $\mathrm{XV}$
}

\section{Brothers and members of a confraternity in the aljama of Toledo in the early fifteenth century}

\author{
Rafael MAYOR \\ Universidad de Salamanca \\ rafaelmayor@usal.es \\ Ana ECHEVARRÍA ARSUAGA \\ UNED \\ aechevarria@geo.uned.es
}

Recibido: 15 de enero de 2015

Aceptado: 3 de junio de 2015

\section{RESUMEN}

Entre 1402 y 1414, la actividad de los miembros de una cofradía vinculada a la mezquita aljama de las Tornerías, en Toledo, quedó registrada por sus autoridades en actas escritas en árabe, demostrando así que éste no había sido olvidado en Castilla a principios del siglo XV. Es la primera cofradía estrictamente mudéjar que conocemos y, a falta de sus estatutos, las actas de sus reuniones facilitan interesantes datos para conocer su funcionamiento. Este artículo abordará las características lingüísticas de la fuente, y un estudio de la cofradía a partir de sus miembros, sus funciones, y su capacidad para gestionar la limosna de los mudéjares toledanos.

Palabras clave: Mudéjar, cofradía, Castilla, medieval.

\begin{abstract}
Between 1402 and 1414, the activity of the members of a confraternity related to the mosque of Tornerías, in Toledo, was registered by their leaders in Arabic proceedings. These records prove that Arabic was still currently used by Muslims in Castile at the beginning of the fifteenth century. This is the first Mudejar confraternity known to us. Lacking knowledge about their statutes, the records of their meetings provide interesting clues to their development. This article focuses on the linguistic features of the records, and will describe the confraternity members, functions, and their capacities to manage Toledan Muslims' alms.
\end{abstract}

Keywords: Mudejar, confraternity, Castile, Medieval.

SUMARIO: 1. El árabe de los documentos, 2. Caracteres lingüísticos, 2.1. Vocalismo, 2.1.a. Timbre, 1.1.b. Cantidad, 2.2. Consonantismo, 2.3. Morfología, 2.3.a. Verbos, 2.3.b. Nombres, 2.4. Sintaxis, 2.5. Léxico, 3. La cofradía y la aljama de Toledo, en el contexto castellano del siglo xv, 4. Funciones de la cofradía, 5. Los cofrades, 6. Limosnas y otros asuntos económicos, 7. Conclusiones. 


\section{EL ÁRABE DE LOS DOCUMENTOS}

Hace tiempo presentamos el estudio, edición y traducción de una documentación que se hallaba entre los papeles de Pascual de Gayangos depositados en la Real Academia de la Historia'. Francisco Fernández y González hace referencia a ella en Estado social y político de los mudéjares de Castilla ${ }^{2}$ pero esta se perdió entre los papeles de Gayangos.

Dicha documentación se compone de once hojas sueltas escritas por, al menos, cuatro manos diferentes, como veremos, y en lengua árabe con caracteres árabes. Las hojas están datadas entre los años 1402 y 1414 y recogen las actas de reuniones de los miembros de la cofradía de la aljama de Toledo. Y aquí radica su importancia. Porque, dejando a un lado otros aspectos no menos importantes, por una parte, nos permite comprobar que el sistema onomástico árabe se mantiene en los documentos internos de la aljama en la primera mitad del siglo XV. Por otra parte, esta documentación es el testimonio de la presencia viva de la lengua árabe entre los musulmanes de Castilla en una fecha tan tardía como es el siglo XV, como vamos a ver.

A diferencia de otros documentos mudéjares, como la documentación editada y estudiada por Mercedes García-Arenal ${ }^{3}$ o $\mathrm{M}^{\mathrm{a}} \mathrm{Jesús}_{\text {Viguera }}^{4}$, estas actas no son formularios notariales, por lo que no se hizo el intento de escribirlas en árabe clásico. Se trata de las actas de reuniones de los miembros de la aljama de Toledo, para tratar ciertos asuntos concernientes a la comunidad (entierros, matrimonios, limosnas...). Es decir, asuntos internos y, por ello, emplearon la lengua que usaban cotidianamente, quizás para que todo el mundo entendiera lo que se había escrito y/o quizás porque no conocían el árabe clásico ${ }^{5}$, aunque de la propia documentación se desprende, que había entre los cofrades gente de mayor nivel cultural, como jueces, alfaquíes e imames, que podrían conocer en alguna medida el árabe clásico, como se colige de algunas interferencias del árabe fuṣhà, unas veces, por hiperco-

${ }^{1}$ Véase ECHEVARRÍA, ANA y MAYOR, RAFAEL, "Las actas de reunión de una cofradía islámica de Toledo, una fuente árabe para el estudio de los mudéjares castellanos. Años 1402 a 1414", en Boletín de la Real Academia de la Historia, Tomo CCVII, Cuaderno II (mayo-agosto 2010), 258-93.

${ }^{2}$ Véase FERNÁNDEZ Y GONZÁLEZ, Francisco, Estado social y politico de los mudéjares de Castilla, Madrid, 1886/1985, 396-97. Agradecemos a la Dra. Cristina Álvarez Millán su ayuda para la localización de esta fuente.

${ }^{3}$ GARCÍA- ARENAL, Mercedes, "Documentos árabes de Tudela y Tarazona", en Al-Qantara 3 (1982), 27-72.

${ }^{4}$ VIGUERA MOLINS, María Jesús, "Partición de herencia entre una familia mudéjar de Medinaceli”, en Al-Qantara 3 (1982), 73-133. (NOTA MODIFICADA POR RAZONES DE ANONIMATO)

${ }^{5}$ A este respecto, encontramos similitudes en otros lugares del Occidente islámico. Es lo que ocurre, por ejemplo, en la documentación tunecina del siglo XVI conservada en el Archivo General de Simancas. Véase EL HOUR, Rachid, "Réflexions historiques et linguistiques sur les documents arabes de Tunisie de l'Archivo General de Simancas", en M. Meouak, P. Sánchez y Á. Vicente (eds.) De los manuscritos medievales a internet: la presencia del árabe vernáculo en las fuentes escritas, Zaragoza, 2012, 121-34. 
rrección, como es el caso de, por ejemplo, ان يغرام عشرون مثنقال (f. 5r)', por عشرين مثنقال; otras veces por la inclusión de lo que sería una fórmula notarial: وبصحة ذاللك وثثبونه (f. 1 r, f. 3v, f. 5r, f. 5v, f. 9v). Como ya hemos dicho, se pueden apreciar varias manos en los documentos. A pesar de que es difícil hacer comparaciones precisas entre las distintas caligrafías, creemos que puede haber hasta cuatro manos diferentes, cada una de las cuales redactó varios folios. Siguiendo el orden de las diferentes hojas de la documentación, un primer grupo estaría formado por f. 1r, f. 3r, f. 4r, f. 4v y la primera mitad de f. $5 \mathrm{r}$. Nos encontramos ante la caligrafía más clara de los cuatro grupos, de trazo fino. Un segundo grupo, está formado por f. $2 \mathrm{r}, \mathrm{f}$. $2 \mathrm{v}$, f. $6 \mathrm{r}, \mathrm{f}$. $6 \mathrm{v}$, f. 7 r, f. $7 \mathrm{v}$, f. 8r, f. 8v, f. 9r y f. 9v. Como se ve, es el grupo más numeroso. La caligrafía es de trazo más grueso que la anterior y más descuidada. En f. $8 \mathrm{v}$ aparecen varias firmas. Una de ellas es la de Yaḥyà b. 'Abd al-Șamad b. Yaḥyà al-Anșārī y su caligrafía se parece bastante a la de los documentos, por lo que podría haber sido él quien redactase este grupo. El tercer bloque, está formado por $\mathrm{f} .3 \mathrm{v}$ (que se encuentra cosido a f. 3r), f. 10r, f. 10v, f. 11r y f. 11v. La caligrafía es más cuidada que la anterior y se parece a la del primer grupo, aunque no es tan cuidada como esta. Al final de f. $3 \mathrm{v}$ también encontramos varias firmas, entre ellas las de Muhammad b. Yūsuf al-Qaysī. Como en el caso anterior, la letra se parece mucho a la de los documentos y puede que fuera él el redactor. El cuarto y último grupo, es el más reducido, formado sólo por la segunda mitad de f. $5 \mathrm{r}$ y por f. $5 \mathrm{v}$. La caligrafía es similar a la del grupo anterior y a la del grupo primero, pero el trazo es más grueso y hay diferencias apreciables. Al final de f. $5 \mathrm{v}$, vemos un grupo de cuatro firmas. La primera de ellas es la de Aḥmad b. Abrāhīm b. Muḥammad al-Lajmī alŠarafì. Como en los dos grupos anteriores, la caligrafía de esta firma es muy similar a la del resto del folio. Quizás fue escrito por al-Šarafĩ.

Dicho esto, no es nuestra intención hacer un estudio pormenorizado del árabe andalusí (o, más concretamente, del árabe andalusí de Toledo), puesto que este ya ha sido estudiado por Federico Corriente ${ }^{7}$ y por Ignacio Ferrando ${ }^{8}$. En este sentido, no nos queda más que decir que en estos documentos encontramos, claramente, características propias de aquel, como, por ejemplo, la imāla o el acento de intensidad ${ }^{9}$. Por ello, nos limitaremos a indicar algunos ejemplos y aquellos casos que sean más relevantes.

\footnotetext{
${ }^{6}$ Nos remitimos a la foliación de los documentos tal y como aparece en ECHEVARRÍA, ANA y MAYOR, RAFAEL, "Las actas de reunión".

${ }^{7}$ CORRIENTE, Federico, A Grammatical Sketch of the Spanish Arabic Dialect Bundle, Madrid, 1977 y CORRIENTE, Federico, Arabe andalusi y lenguas romances, Madrid, 1992.

${ }^{8}$ FERRANDO, Ignacio, El dialecto andalusi de la Marca Media: Los documentos mozárabes toledanos de los siglos XII y XIII, Zaragoza, 1995 y FERRANDO, Ignacio, "Algunos aspectos fonológicos de los subdialectos andalusíes de Toledo", en EDNA 1 (1996), 113-25.

${ }^{9}$ Véase, por ejemplo, CORRIENTE, Federico, Arabe andalusí, p. 60 y CORRIENTE, Federico, “Árabe andalusí,", en F. Corriente y Ángeles Vicente (eds.), Manual de dialectología neoárabe, Zaragoza, 2008, 353-78.
} 


\section{CARACTERES LINGÜÍSTICOS}

\subsection{VOCALISMO}

\section{1.a. TIMBRE}

En la documentación analizada, no hay apenas vocales. Las pocas que aparecen las podríamos insertar en alguno de estos tres grupos de palabras:

a) Palabras castellanas ${ }^{10}$, incluidos nombres propios. Por ejemplo: البُريخِونيُو (f.

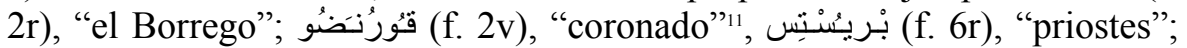
لوَبْ (f. 6r), "Lope".

b) Encontramos un segundo grupo de palabras vocalizadas en las que parece que se respeta la vocalización del árabe clásico. Por ejemplo: وَلَكهُ (f.6r);

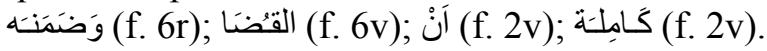

c) $\mathrm{Y}$ un tercer grupo está constituido por palabras en dialecto en las que parece que el escriba incluye las vocales para evitar confusiones, como por

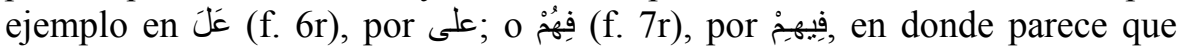
escribe la palabra, tal y como se pronuncia en dialecto y, quizá, sea consciente de que la palabra en árabe clásico no es así. En otros casos, sobre todo en los verbos, pero no sólo, la vocal indica el lugar en el que debería estar una letra de prolongación, en el árabe clásico, y que en dialecto ha desaparecido como tal, pero cuyo sonido sigue existiendo: وَامرَ (f. 2r), por

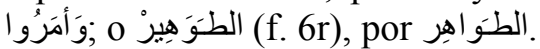

Y, en cuanto al tanwīn, como era de esperar, no aparece en los documentos más que de manera esporádica: بستة عشرة مثنقال (f. 3v); من كل واحدٍ (f.5r); y lo que podría ser un

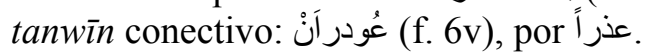

Por otro lado, podemos confirmar la existencia de imāla, pues nos encontramos con

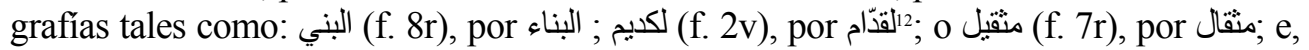

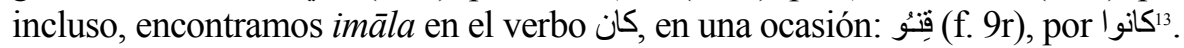

Además, la imāla también está presente en el plural femenino sano, con grafías como جلويت (f. 10r), por جلوات.

Y parece que la imāla se extiende incluso al relativo: مِ مِ (f. 2v), por مِز ادو o (f. 6r), por ماز ادوا

${ }^{10}$ Véase más adelante el apartado 5.- Léxico.

${ }^{11}$ Posiblemente, el "cornado" que recoge el DRAE para la segunda acepción de "coronado": "Moneda antigua de cobre con una cuarta parte de plata, que tenía grabada una corona, y corrió en tiempo del rey Sancho IV de Castilla y de sus sucesores hasta los Reyes Católicos". Véase: www.rae.es.

${ }^{12}$ Donde, además, observamos un fenómeno de desvelarización de la /q/ en /k/. Véase más adelante el apartado 1.2.- Consonantismo.

${ }^{13}$ Aquí también se produce una desvelarización de la /q/ en /k/, además de una caída de la alif de كان, que debía de pronunciarse con imala, como indica la kasra residual. 
Por otro lado, parece que el fonema /o/ del romance está presente. Así, a final de palabra se representa con / قرقجو او/, como en (f. 7v), "Caracacho", اشتجظو / 0 (f9r), "escuchado" o "excusado" ". Otras veces, se escribe representa con una simple $h \bar{a}$, final: مايه (f. 4r y f.7r), "mayo"; القرقجه (f. 3v), "el Caracacho". Para esta palabra, también encontramos la forma قرقج (f. 11r), que quizá sea un simple descuido, habiéndose olvidado el escriba de la alif tras la $w \bar{a} w$, puesto que unas pocas líneas más abajo aparece قرقجوا.

En otras posiciones, el fonema /o/ puede representarse con una waw, como en الاشقجظوش (f. 3r), "los escuchados" o "excusados".

\section{1.b. CANTIDAD}

Como dice Federico Corriente, "el andalusí no conservaba el ritmo cuantitativo del árabe antiguo, habiéndolo sustituido por un sistema de prominencia silábica basado en el acento tónico como fonema suprasegmental" ${ }^{15}$. Es por ello por lo que nos encontramos con palabras en las que hay matres lectionis en posiciones que debían de

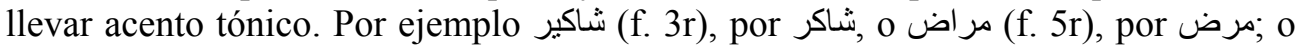

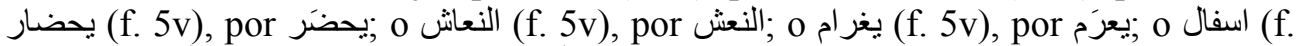
5v), por أشهور o أسفل o أنشرُ (f. 6v), entre otras muchas más.

Y, por el contrario, se tiende a suprimir las matres lectionis de las sílabas que no

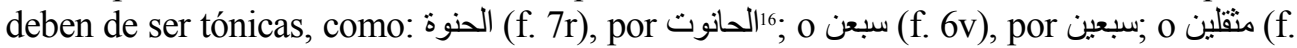

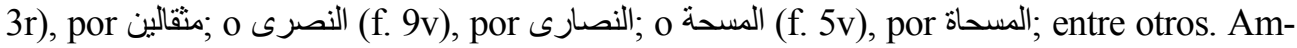
bos casos se pueden dar en una misma palabra, como en الثرور (f. 6r), por الثنشروط

En otras ocasiones, la letra de prolongación simplemente desparece, como en جنزة (f. 9r), por alguna ocasión, la kasra de la preposición بـ se prolonga en $y \bar{a}$ ': بيمائة (f. 9r), pel mismo modo que, también en algunas ocasiones, la kasra de كلّ también se prolonga en $y \bar{a}$ ' كلي (f. $2 \mathrm{v}$, f. 7r y f. 8v), podemás de su variante قلي (f. 2v, f. 6r, f. 6v, f. 7r, f. 9r y f. 9v), donde se produce, además, velarización de la $/ \mathrm{k} /$ en /q/. Y, también en ocasiones, se prolonga la vocal del pronombre masculino plural en tercera persona: هوم (f. 8v y f. 9v), por هُم

${ }^{14}$ Aunque en la traducción de los documentos se optó por interpretar esta palabra como "escuchado/s", en virtud de las grafías explicadas en el apartado anterior, el estudio de otras particularidades de estos y otros documentos permiten suponer que esta palabra podría ser la transcripción de "excusado/s". Por ejemplo, en estos documentos aparece, varias veces, el nombre ترجـ (Teresa). Vemos que la /s/ intervocálica ha sido transcrita con una yim y esto mismo podría haber ocurrido con por اشقجظو lo que podría tratarse, por lo tanto de "excusado/s", como hemos dicho. Estos "excusados" serían aquellos que no tenían obligación de pagar los impuestos repartidos entre la comunidad por su categoría social o por gozar de alguna franquicia otorgada por el rey.

${ }^{15}$ Véase, por ejemplo, CORRIENTE, Federico, Arabe andalusí, 60 y ss.

${ }^{16}$ Palabra en la que, además, vemos que se emplea la $t \bar{a}$ ' marbūta como grafía de la $t a$ ' final, como veremos en más casos.

${ }^{17}$ Donde observamos, además, desvelarización de la /t/ en /t/. 


\subsection{CONSONANTISMO}

En lo que se refiere al consonantismo, notamos una casi total ausencia de hamza, lo que indica, con toda probabilidad, que esta no se realizaba. Se mantiene en algunos pocos casos, como: هو لاء (f. 10v), por هؤ لاء, aunque en todos los demás casos en los que esta palabra aparece se escribe هو لا

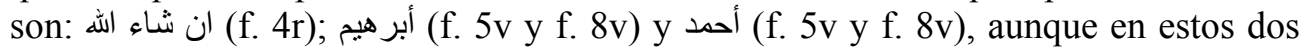
últimos casos se trata de una firma. En entornos /ā-i/, la hamza es sustituida por una $y \bar{a}$, como en: زايد (f. 7v), por العوايد o j ز ائد (f. 1r, f. 3r, f. 3v, f. 5r, f. 5v y f. 6v), por العوائد. Se trata de igual manera la hamza de أسماء en la expresión ختمو السمايهم (f. 1r, f. 3v, f. 5r, f. 5v, f. 9v), por ختموا أسماءَهم.

En cuanto a la palabra مائة, siempre se escribe مايه a final de palabra, la hamza o bien simplemente desaparece, como en ll (f. 2r, f. 3r, f. $3 \mathrm{v}$, f.4v, entre otros), por البناء, o bien se escribe como alif maqșūra: نِنَى (f. 9r), por نساء, lo que parece indicar que la hamza ha desaparecido, quedando un simple sonido /a/, que es representado con una alif maqșüra, que, además, es como, a veces, se escribe la tà' marbüt ta, como veremos.

Por otro lado, nos encontramos con frecuentes casos de realización de la /d/ co-

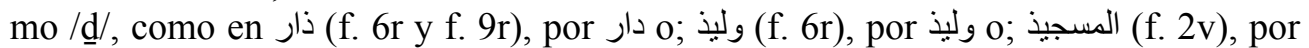

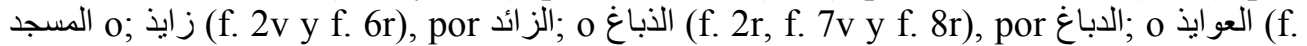

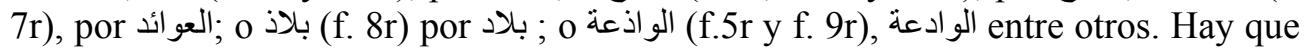
aclarar que tanto en estos casos como en los demás que veremos, los cambios no son sistemáticos, sino que unas veces se producen y otras no.

En otras ocasiones, lo que ocurre es lo contrario, la realización como /d/ de la

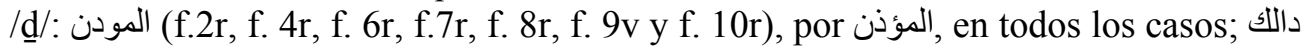
(f. 2v, f. 6r, f. 6v, f. 7r, f. 7v, f. 8v y f. 9r), por ذلك

Mientras que, otras veces, la /d/ se velariza en /ḍ/: للضار (f. 9r), por y la /d/ en /ẓ/: عظر 8f. 5r), por عذر.

También observamos que parece que hay una realización africada de la /ḍ/ como $/ \mathrm{z} /$, puesto que es frecuente la sustitución de /ḍ/ por $/ \mathrm{z} /$, como, por ejemplo,

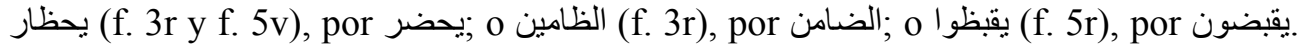

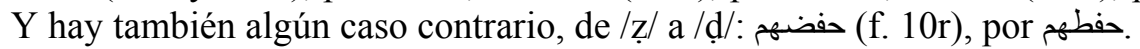

Parece confirmar la posible realización africada de /d/ y de /ḍ/ la representación del fonema /d/ intervocálico en las palabras castellanas, pues es frecuente escribir

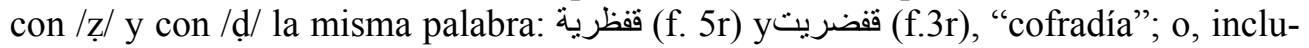

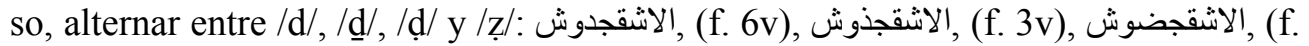
3r) y الاشقجظوش, (f. 3r), "escuchados" o "excusados".

También encontramos algunos casos de confusión entre /s/ y /ṣ/. Por ejemplo:

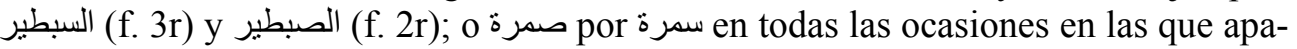
rece esta palabra en las actas.

En cuanto a la /t/, en ocasiones se relaja y se desvelariza en /t/, como التريق (f.

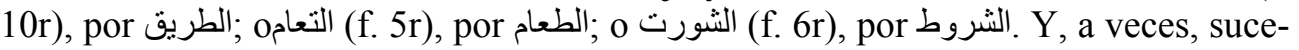


de lo contrario: el paso de /t/ a /t/, como en الطاسع (f. 3r), por الطر اب o استع (f. 10r), por التراب

En otras ocasiones, la que se desvelariza es la /q/, como, por ejemplo, en: لكديم (f.

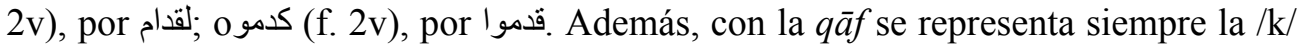

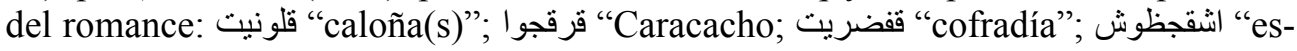
cuchados" o "excusados"; قورنضوس آن "coronados".

En cuanto al fonema /p/, parece que estaría presente en préstamos del romance, como en بروشتيش (en todas sus variantes) o en لوب "Lope".

Parece que el fonema /č/ del romance estaría representado como yim, como ya hemos visto en قرقجو (f. 7v), "Caracacho".

En cuanto a la $t \bar{a}$ ' marbüta, tenemos que decir que, en general, aparece sin diacríticos y que, en ocasiones, es sustituida por una alif, que puede ser, o bien mamdüda, como en زوجا (f. 10v), por زوجة, o bien maqșüra, como en جمعى (f. 2v),

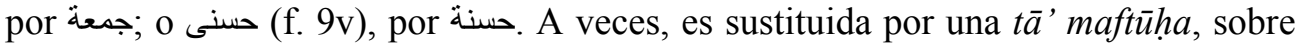
todo en anexión: قفضريت (f. 18 vivرية Además, hay un caso en el que la $t \vec{a}$,

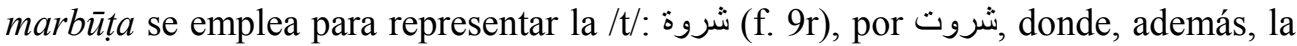
/ț شروط se ha desvelarizado en /t/, que es la que se representa con la tä' marbüta.

Muchas veces, la preposición في pierde la $y \bar{a}$ ' y se une a la palabra que la sigue,

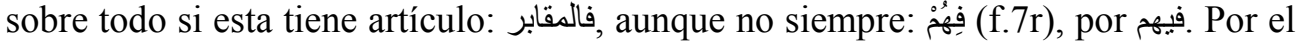
contrario, a veces se prolonga la kasra de la lām de la partícula لـ, como en لي معلم (f.9r), por لِمع

La alif maqșūra a veces desaparece del final de la palabra, como en: لَ́ (f. 6r),

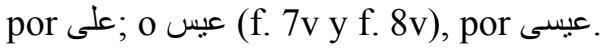

En cuanto a la geminación, la šadda aparece en muy pocas ocasiones. Sólo en

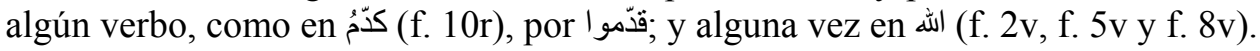

\subsection{MORFOLOGÍA}

\section{3.a. VERBOS}

Hay una total ausencia de la nün del masculino plural en los verbos en imperfectivo. En este punto, hay tres posibilidades:

1) La nün desaparece y se incluye una alif, como si el verbo estuviera en subjuntivo o en yusivo: يكولو (f. 1r), por يأكلون.

2) Otras veces, la nün simplemente desaparece y no se añade nada: يخدمو (f. 9v), por يخدمون.

3) La tercera posibilidad es que desaparecen tanto la nūn como la $w \bar{a} w$, marcándose el plural con una ḍamma: يكلُ (f. 5v), por يأكلون.

\footnotetext{
قفضريت جامع الو اديعة 18
} 
En la tercera persona del masculino plural del verbo en perfectivo, a veces se omite la alif ortográfica después de la wāw: أكلو (f. 7r), por ألكرو o أخو (f. 7r), por أخرو. Otras veces la $w \bar{a} w$ se sustituye por una damma sobre la última letra, como ya he-

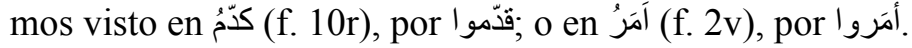

En cuanto a los verbos hamzados, como ya hemos visto que la hamza ha desaparecido, pueden ocurrir varias posibildades:

1) Puede ocurrir que, al caer la hamza, se marque lo probable sílaba tónica con una mater lectiones, como en يخوذ (f. 9r), por يكولوا (f. 1r), por ئ en oأخلون.

2) Otra posibilidad es que la hamza sea sustituida por una alif, sobre todo a principio de palabra, como en: أكلو (f. 7r), por أكلوا' aunque también se produce en posiciones mediales: يقراو (f. 9r), por يقرؤ أول

3) La tercera posibilidad es que desparezca la hamza sin dejar rastro. يكلون (f. 5r), por يأكلون.

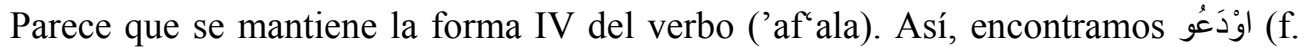
6r); por أودرَجو o أودوا (f. 9v), por أخروا.

Y se conserva la voz no agentiva de marcación interna, según parecen indicar formas como: يغر ام (f. 5r), por يغرَم, en el imperfectivo o نُبِ (f. 5r), en el perfectivo.

\section{3.b. NOMBRES}

En cuanto al nombre, daremos unos breves comentarios.

Debemos señalar que aparece el dual, como en اليومين (f. 6v); o منقلين (f. 3r), por مثقالين موج Sin embargo, también se emplea significado de "dos", como en 2 (f. 9v), “dos coronados 2”.

En los numerales cardinales, destacaremos que la cosa numerada no aparece en plural, cuando se trata de números del 3 al 7: عشرة مثقال (f. 5r), por عشرة مثاقيل. Por otra parte, se confirma lo que Federico Corriente apunta: la caída de /-ar/ final en

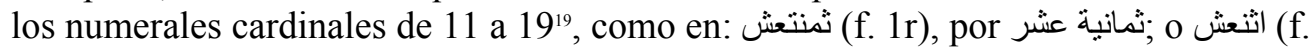
6v), por اثثي عشر.

En lo referente a los pronombres personales, aunque en los documentos hay muy pocos, sí podemos destacar que aparece una forma هوم (f. 8v y f. 9v), por هُ como ya hemos visto al final del apartado 1.2, y un pronombre de tercera persona masculino singular sufijado que se representa con una wāw: صَحِيُو (f. 7r), por صحاحِبه o يعطي له ئه (f. 9r), por.

El pronombre relativo es الذي (f. 2v, por ejemplo), invariable, que, a veces, se escribe الدي (también en f. 2v). Además encontramos un relativo (con imāla) en من كن (fv). كلي مي ينبغي (f. 2v).

${ }^{19}$ CORRIENTE, Federico, Árabe andalusí, 92 y CORRIENTE, Federico, “Árabe andalusí”, 367. 
El pronombre demostrativo no está representado en todas sus personas en los documentos. Aun así, podemos confirmar la existencia de (f. 1r), que, en tres

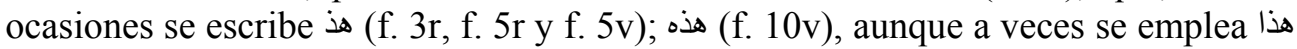

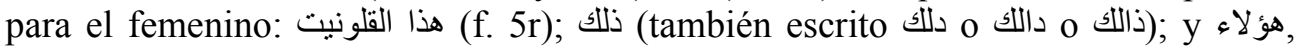
siempre escrito هو لا (aunque en una ocasión aparece como هو لاء, en f. 10v).

\subsection{SINTAXIS}

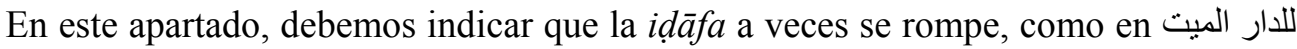

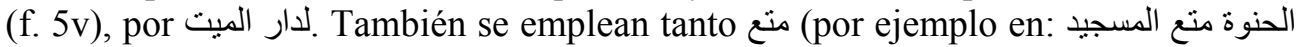

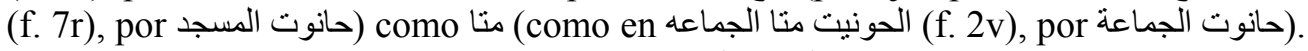

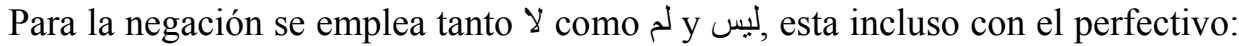
من الذي ليس حضار (f. 8v).

Se utiliza بش بش برمي : بر (f. 9r) y se

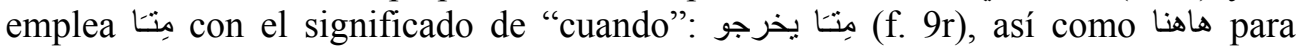
"ahora" (f. 10v, por ejemplo).

\subsection{LÉXICO}

En cuanto al léxico, decir que la influencia del romance es notable. Y ello en una doble vertiente.

Por un lado, nos encontramos con calcos sintácticos, como زوجا كانت للمعلم احمد (f. 4v), "mujer que fue del maestre Ahmad" y زوجا كانت للغلب (f. 10v), "mujer que fue de al-Gālib".

Además, tenemos calcos semánticos, como el empleo de la palabra معaestro, instructor), que, claramente, está traduciendo el romance "maestre".

Por otro lado, hay que mencionar la existencia de palabras tomadas directamente del romance. Un primer grupo sería el formado por los nombres propios, como, por ejemplo:

- Borrego (el): البورغو (f. 2r).

- Caracacho: قرقجو الوغر : (f. 2r, f. 4r, f. 4v, f. 5r, f. 6r, f. 7v, f. 10r, f. 10v y f. 11r), قرقجه (f. 3v y f. 9v) y قرقجو (f. 11r).

- Coronel: قرنيل (f. 8v).

- García: غرسية (f. 2r, f. 4v, f. 5r, f. 6r, f. 7v y f. 11r).

- Juana: جوانة (f. 3r).

- Lope: لوب (f. 6v y f. 7r) y (f. 11r).

- María: مري (f. 8v).

- Fernández (f. 8v). 
- Teresa: ترجة (f. 3r, f.4v, f. 5r, f. 10v y f. 11r).

Otro segundo grupo es el formado por los topónimos y los gentilicios:

- Ajofrín: اجفرين (f. 11r).

- Burgos: برغس (f. 2r), برغوش (f. 8r) y برغ (f. 9v).

- Cadrete: فظريطي (f. 4r).

- Conquense (el): الكنكي (f. $4 \mathrm{r}$ y f. 7v).

- Escalona: انقلونة (f. 4v y f. 11r).

- Illescas: الايشك (f. 4v y f. 11r).

- Magán: مغن (f. 5r).

- Ocaña: اوقنية (f. 2r, f. 3v, f. 4r, f. 4v, f. 8r y f. 10v) y اقنية (f. 3r).

- Segovia: شغبية (f. 10v).

- Sonseca: شنشقة (f. 4v y f. 8r).

- Talavera: طلبيرة (f. $4 \mathrm{r}$ y f. 8r).

- Uclés: اوقليج (f. 4v, f. 8r y f. 11r).

Un tercer grupo lo constituyen los nombres de los meses:

- Febrero: فبرير (f. 5r).

- Mayo: مايه (f. 4r y f. 7r).

- اعوشت اغشت (f. اغش (f. 8v).

- Noviembre: نونبر (f. 3r).

- Diciembre: ذونبر (f. 3v) y نيجنبر (f. 6r).

$\mathrm{Y}$ un cuarto grupo está formado por otro tipo de palabras:

- Caloña(s): قلونيت (f. 1r, f. 3r, f. 3v, f. 5r, f. 5v, f. 6r, f. 6v, f. 7r, f. 10v y f. 11v) y قلونية (f.5r).

- Coronado(s): قورنضو (f.2v, f. 6v y f. 7r) y قورنضوس (f. 9v).

- Doña: دونية (f. 3r y f. 8v) y ذونية (f. 3r, f. 4v, f. 5r, f. 10v y f. 11r).

- Cofrade: فقظر (f. 8v).

- Cofradía: قفضريت (f. 3r, f. 3v, f. 6r, f. 7r y f. 9r), قفظرية (f. 5r y f.5v).

- Escuchado(s): الاشققذوش (y todas sus variantes). 
- Priostes: بروشتش (en todas sus variantes).

- Zapatero: الصبطير (f. 2r y f. 8r, ) y الصبطير (f. 4r, f. 4v y f. 8r, ).

A pesar de que, como hemos dicho, no hemos realizado un estudio en profundidad de la lengua de las actas, queda claro, a través de todo lo que hemos expuesto, que la lengua usada en esta documentación pertenece, claramente, al árabe andalusí hablado en Toledo.

También parece claro que se trata de una lengua viva, pues quienes escribieron dichas actas lo hicieron en un idioma que usaban habitualmente. Entre los cofrades había personajes a los que les presuponemos un cierto nivel cultural, pues eran jueces y alfaquíes, y que, seguramente, conocían el árabe clásico, pero decidieron redactar las actas tal y como hablaban, empleando (como en otras partes del Occidente islámico) el árabe que usaban, concretamente el árabe andalusí.

Es decir, que estas actas nos están diciendo que los musulmanes de Castilla, o al menos los de Toledo, mantenían viva la lengua árabe en el siglo XV, que la hablaban entre ellos. ¿Qué sentido tendría, si no, redactar dichas actas en árabe (y además dialectal) si era un idioma que ni hablaban ni entendían?

\section{LA COFRADÍA Y LA ALJAMA DE TOLEDO, EN EL CONTEXTO CAS- TELLANO DEL SIGLO XV}

Durante la primera mitad del siglo $\mathrm{XV}$, que corresponde a los últimos años del reinado de Enrique III y la regencia compartida por Fernando de Antequera y Catalina de Lancaster de su hijo Juan II, la ciudad de Toledo quedaba lejos del ámbito de las capitales de realengo de la cuenca del Duero, a pesar de seguir siendo una de las principales urbes del reino. La ciudad, entre la égida del arzobispo de Toledo, primado de España, y la influencia de las familias nobiliarias que la habitaban, había visto reducida la presencia de musulmanes en su perímetro a tres áreas principales. Como zonas de vivienda, predominaban en dos barrios: el de san Isidoro (barrio de los alfareros), con su carnicería, y el barrio conocido como de Sancho Minaya, donde se concentraban los musulmanes de buena posición, que habían vendido su casa hacia la segunda mitad del XV. Toda esta zona fue enterrada bajo sucesivas ampliaciones de la catedral ${ }^{20}$. En el barrio comercial de Zocodover se situaban los negocios de artesanía y venta, y se encontraba la mezquita principal de la ciudad, denominada popularmente "del Solarejo" (en referencia a la plaza trasera a la que salía su puerte y su jardín) o "de las Tornerías". Es la única que conocemos activa en la época que nos concierne, y situada en plena zona comercial, en la confluencia entre las calles de los herreros y los zapateros, ambos oficios representados

\footnotetext{
${ }^{20}$ PASSINI, Jean, Casas y casas principales urbanas. El espacio doméstico de Toledo a fines de la Edad Media, Toledo, Universidad de Castilla-La Mancha, 2004, p. 117. Agradezcemos al Prof. Passini sus aclaraciones respecto a estos barrios.
} 
en la cofradía ${ }^{21}$. El hecho de que Toledo contara con una única mezquita conocida, de escaso tamaño, con un pozo en su planta baja y unas tiendas que servían para su mantenimiento, no debe llevarnos a pensar que la comunidad mudéjar de la ciudad fuera muy reducida, como veremos seguidamente. Los documentos nos facilitan el posible nombre en árabe de la mezquita, pues los reunidos se identifican como los hermanos pertenecientes a "la cofradía de yami ' al-Wadi 'a", que podría traducirse como "de la Encomienda"22.

La constitución de cofradías asistenciales, que cubrían a la vez funciones religiosas, caritativas, funerarias y mutualistas, es bien conocida tanto en el Islam como en la Europa cristiana, con especial apogeo a partir del siglo XIII. Hasta ahora, se conocía una cofradía gremial mixta de herreros, la de San Eloy y San Antón, que admitía tanto a cristianos como a mudéjares, y cuyas ordenanzas se conservan en una copia de Segovia de $1484^{23}$. También existían otras cofradías gremiales en Toledo, pero solo cristianas, como la de San Pedro, correspondiente a una parroquia y su hospital de pobres anejo, cuyos libros de cuentas se han conservado para 14551458 y 1485-1498; o la de mercaderes de Santa María de la O, cuyas ordenanzas son de $1485^{24}$. Sin embargo, y a pesar de que en el reino de Granada sí parecen haber proliferado tarīqas y cofradías, hasta ahora no nos constaba la existencia de ninguna en el contexto mudéjar ${ }^{25}$. La vinculación a la mezquita, expresada en las propias actas, la variedad de oficios representados entre los cofrades y el número de

${ }^{21}$ Sobre esta mezquita, véase DELGADO VALERO, Clara, "La estructura urbana de Toledo en la época islámica", en Regreso a Tulaytula. Guía del Toledo islámico (siglos VIII-XI), Toledo 1999, 15155, espec. 83-84; PORRES MARTÍN-CLETO, Julio, “¿Restos de una mezquita toledana?”, AlAndalus XLIII (1978) 455-459 y "La mezquita toledana del Solarejo, llamada de las Tornerías", $A l$ Qantara IV (1983) 411-421. El autor sostiene que la mezquita de las Tornerías o del Solarejo reemplazó a la del Salvador como la principal de Toledo.

${ }^{22}$ Otra posible traducción del término sería "cofradía del adiós", haciendo referencia a los fines funerarios de la misma, pero ni éstos eran únicos, ni queda del todo claro, puesto que, aunque wada, de la misma raíz, es "despedida", haría falta una imala de segundo grado para pasar a ser wadi", a la que se añadiría una ta' marbuta. Aun así, y aunque sea posible una revisión, preferimos el significado dado de "custodia", "depósito", quizás por el dinero que recogen; o "encomienda", como ya hemos dicho.

${ }^{23}$ CONTRERAS, Juan, Historia de las corporaciones de menestrales en Segovia, Segovia, 1921, 119-127, cit. ASENJO GONZÁLEZ, María, La Extremadura castellano-oriental en el tiempo de los Reyes Católicos: Segovia (1450-1516), Madrid 1984, vol. 1, 330-331. Nueva edición paleográfica sin mayor comentario en GÓMEZ GARCÍA, Luz, "Los mudéjares menestrales segovianos", Sharq alAndalus 14-15 (1997-98) 35-45.

${ }^{24}$ MOLÉNAT, Jean Pierre, "Menus de pauvres, menus des confrères à Tolède dans la deuxième moitié du XVe siècle", en Manger et boire au Moyen Âge. Actes du Colloque de Nice (15-17 octobre 1982), Aliments et Société, Paris, 1984, tomo 1, 313-318; GONZÁLEZ ARCE, José Damián, "La cofradía laboral como precedente del gremio: los mercaderes de Toledo durante el reinado de los Reyes Católicos”, En la España medieval 31 (2008) 177-216.

${ }^{25}$ RODRÍGUEZ-MAÑAS, Francisco, "Encore sur la controverse entre soufis et juristes au Moyen Âge: critiques des mécanismes de financement des confréries soufies", Arabica $43 / 3$ (Sep., 1996) 406-421. 
asistentes a las reuniones -entre 77 y 95 personas adultas según el año ${ }^{26}$ - hacen pensar que en la cofradía estaban recogidos prácticamente todos los miembros de la comunidad mudéjar toledana, e incluso cabría pensar en algunos invitados transeúntes.

La frecuencia de las reuniones que se consignan debió ser anual, a juzgar por la secuencia de los documentos fechados, 1402-1403-1404-1405, con una interrupción posterior hasta 1408-1409-1410-1411 y finalmente, 1414; además, contamos con varias actas más sin datar, que podrían corresponder a alguno de los años intermedios. Ello nos permite tener una radiografía de la aljama de Toledo durante todo el primer cuarto del siglo XV. Es interesante ver que la interrupción en los documentos coincide con dos momentos peligrosos para las comunidades mudéjares del sur de Castilla: la preparación y desarrollo de la campaña cruzada del infante Fernando que condujo a la toma de Setenil, en 1406-1407, y la etapa posterior a la predicación de fray Vicente Ferrer en la propia ciudad de Toledo, acompañada de la publicación del ordenamiento de Valladolid en el que se censuraban las costumbres de moros y judíos. Sin embargo, en los documentos sólo se trata de asuntos internos, por lo que no se halla ninguna referencia a estos hechos, y también es posible que la falta de actas para esos dos periodos se deba a meras cuestiones de conservación.

\section{FUNCIONES DE LA COFRADÍA}

Como hemos dicho previamente, la cofradía servía a varias funciones, ligadas todas al desarrollo de las prácticas religiosas de los mudéjares, y especialmente para su sostén en la práctica de los pilares del Islam. Respecto a la primera, queda de manifiesto en la reunión de 1405, "que están en la cofradía de la mezquita/aljama al-

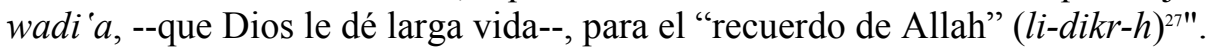

\footnotetext{
${ }^{26}$ Por ejemplo, en la reunión de 1402 se realiza un listado para pagar la limosna que incluye a todos los miembros de la cofradía, asistan o no, que arroja una cifra de 86 personas. En 1409 se mencionan 77 personas, aumentadas en el acta de 1410 a 81 personas y en 1411, a 95 personas, quizá un número muy alto para ser cofrades, y que podría responder más bien a los cabezas de familia de la aljama. Para todos estos datos, y con el fin de evitar repeticiones innecesarias, véase la publicación de las actas en ECHEVARRÍA, Ana y MAYOR, Rafael, "Las actas de reunión", en los años mencionados. Si en Toledo se repartieron 8.500 maravedíes en concepto de servicio y medio servicio en 1463, muchos años después de esto, y teniendo en cuenta la estimación de población de Ladero Quesada, no parece descabellado pensar que el número total de mudéjares que habría en la ciudad a principios del XV estaría en torno a los 380-495 habitantes. A fines de siglo las pechas oscilaban entre 43 y 46 , lo que indica un número excesivamente bajo de vecinos comparados con principios de siglo, incluso teniendo en cuenta a los excusados de pagar impuestos. VIÑUALES, Gonzalo, "El repartimiento de servicio y medio servicio de los mudéjares de Castilla en el último cuarto del siglo XV", Al-Qantara XXIV (2003) 179-202; LADERO QUESADA, Miguel Ángel, "Datos demográficos sobre los musulmanes de Granada y Castilla en el siglo XV", Anuario de Estudios Medievales 8 (1973) 481-490, concretamente 488 .

${ }^{27}$ ECHEVARRÍA, Ana y MAYOR, Rafael, “Las actas de reunión”, f. 3v.
} 
Las cuestiones religiosas debatidas incluyen la regulación de las celebraciones comunitarias más públicas de la cofradía, siguiendo las costumbres propias, que no necesariamente aparecen consignadas en los libros de teoría jurídica que tratan de estos actos. Entre ellas, figuraban los acontecimientos familiares, que pasaban a formar parte de las obligaciones cotidianas de los cofrades, y también muestra de una solidaridad religiosa y comunitaria. Los miembros de la cofradía -y probablemente también sus familiares- tenían la obligación de asistir a las bodas y los convites de la dote, contribuyendo con un metical a los gastos del novio, o pagar una multa ${ }^{28}$. El siguiente rito en el que se los encuentra es en la circuncisión de los niños de la casa ${ }^{29}$.

La participación de los cofrades en los ritos funerarios era una forma de garantizar que éstos se realizaban correctamente, y siguiendo todas las indicaciones y prescripciones de pureza necesarias, así como la inviolabilidad de su cementerio ${ }^{30}$. Estas prácticas fortalecían la identidad comunitaria mudéjar y creaba espacios de convivencia en una sociedad hasta cierto punto hostil. Dado que los estatutos u ordenanzas de la cofradía han desaparecido, no sabemos exactamente cómo se desarrollaba la parte pública de los entierros, en la que participaban, excepto por las breves matizaciones que proporcionan las reuniones. Dos de éstas -las de $1408 \mathrm{y}$ 1414- se ocuparon especialmente de definir la actuación de los cofrades, tanto hombres como mujeres, en los entierros ${ }^{31}$. Además de las acostumbradas visitas de pésame a la familia del finado, se requería que alguno de los cofrades estuviera presente durante el amortajamiento y que diera después testimonio del fallecimiento ante el juez. Después, los cofrades debían escoltar el féretro hasta el cementerio, desde que era sacado de la casa, y llevado a hombros por ellos mismos. Los que no asistieran serían multados con dos meticales, mientras que los que no ayudaran a utilizar la pala tendrían que pagar un metical.

La participación en los cortejos fúnebres era considerada meritoria en el Islam para el perdón de las faltas del creyente. Pero también constituía una parte importante de la visibilidad de la comunidad, y por ello tanto los priostes elegidos por la cofradía como los mayores y más respetados miembros de la aljama debían transportar el féretro y la pala. Una vez en el cementerio, la excavación de la tumba podía ser realizada por los sepultureros, siguiendo las indicaciones recogidas por el Breviario sunní, la Risāla de al-Qayrawani o el Tafrī', pero una vez más eran los propios cofrades y familiares quienes debían participar a la hora de arrojar tierra sobre el féretro del difunto, a manera de homenaje final, siendo multado quien no lo

${ }^{28}$ ECHEVARRÍA, Ana y MAYOR, Rafael, "Las actas de reunión”, f. 4v, 10r. Otra mención breve en f. $2 \mathrm{v}$ y $10 \mathrm{v}$.

${ }^{29}$ ECHEVARRÍA, Ana y MAYOR, Rafael, "Las actas de reunión”, f. 6r.

${ }^{30}$ Estos ritos han sido estudiados para el contexto mudéjar castellano en ECHEVARRIA, Ana, "Islamic Confraternities y Funerary Practices: hallmarks of Mudejar identity in the Iberian Peninsula?", Al-Masaq: Islam y the Medieval Mediterranean 25 (2013) 1-24.

${ }^{31}$ ECHEVARRÍA, Ana y MAYOR, Rafael, "Las actas de reunión”, f. 4r-6r, 9r-10v. 
hiciera $a 1^{32}$. Los funerales se dirían sobre la tumba "del pariente o de la madre que pague el alimento" durante dos días, quedando prohibidos después de ese tiempo los funerales en el cementerio, tanto de hombres como de mujeres. Si se celebraba más de un funeral a la vez -hecho habitual en periodos de peste, por ejemplo-, la familia del muerto podía salir al cemeterio para leer la azora al-Fatiha, y los miembros de la cofradía debían acompañar a los familiares de unos y otros sucesivamente, o bien podían realizarse dos funerales en la mezquita al amanecer. Quien no lo cumpliera, sería multado con un metical, excepto los ancianos de más de sesenta años, el cadí, los alfaquíes y el imam; el resto de los viejos de la aljama debía sacar el féretro de casa del muerto. El luto duraba un mes, y eximía a la familia de participar en todos actos públicos de la comunidad.

Estos fines coinciden en líneas generales, y salvando las distancias, con los de las cofradías cristianas. Ante todo, destacan los fines piadosos, establecidos y sancionados por la Partida V, VII, ley II: "para dar de comer a los pobres y para iluminar y soterrar a los muertos". La iluminación se refería a la compra de velas para el mantenimiento del culto en la iglesia correspondiente -en este caso, la mezquita. Los testimonios escritos comienzan a aparecer en el siglo XIV, debido al interés por codificar la actuación de las cofradías, que así se pueden someter a la aprobación de la autoridad y el seguimiento de sus prácticas por el aparato jurídicoadministrativo laico y eclesiástico. Además, podían dedicarse a la dotación de doncellas pobres para el matrimonio (Hermandad del Hospital del Salvador o de la Misericordia, regla del 1390) ${ }^{33} \mathrm{y}$ el acompañamiento y oración por los difuntos (Hermandad del Hospital del Salvador o de la Misericordia, regla del 1390; del Hospital de Peregrinos de Nuestra Señora del Pilar, 1336; y Cofradía de San Pedro Apóstol o de los guarnicioneros, h. 1450). Ambas actividades repercutían, también en el entorno cristiano, en la trascendencia espiritual del finado, su estima social y su dignidad.

Otro punto común a ambos credos, y a la organización de las cofradías, es que se da cabida a las mujeres en ellas, con el nombre de "hermanas o cofradas", con personalidad propia y capacidad de decisión, ejerciendo si es necesario como cabezas de familia, en el caso de las viudas. En la cofradía mudéjar toledana se hace especial referencia a este extremo al mencionar el prestigio del que goza la "la madre que pague el alimento" ${ }^{34}$. No solo se observa en la disposición de dos días de funeral sobre su tumba, lo mismo que sobre la tumba de los varones de la comunidad, así como en la utilización del título "doña" para referirse a ellas, sino que además son mencionadas como cabezas de familia y personas independientes en las

\footnotetext{
${ }^{32}$ Breviario sunni, Ms. 2076, Biblioteca Nacional Madrid, f. 29v; S. Abboud-Haggar (trad. y ed.), El tratado jurídico de al-Tafrī $`$ de Ibn al-Ğallāb. Manuscrito aljamiado de Almonacid de la Sierra, Zaragoza, 1999, vol. II, 174-175; y actas mencionadas en nota anterior.

${ }^{33}$ SÁNCHEZ HERRERO, José y PÉREZ GONZÁLEZ, S. M., CXIX Reglas de Hermandades y Cofradias Andaluzas, ss. XIV, XV Y XVI, Huelva, 2002.

${ }^{34}$ ECHEVARRÍA, Ana y MAYOR, Rafael, "Las actas de reunión”, f. 10r.
} 
actas de reuniones de la aljama, con sus propias cargas de impuestos o limosnas, etc. Nombres conocidos asisten a la reunión de la cofradía toledana en 1411, fecha coincidente con los datos de su actividad profesional, como los de doña Zuhra, que fue la esposa del maestre Ahmad \{H.y.l.bo\} y se relaciona con María Fernández Coronel; doña Šamsī la comadrona, que fue la esposa de al-Galib, suegra del alfaquí Yuçaf Cadrete y a quien ya conocíamos por otra documentación toledana. También Doña Fátima al-qābila, que ejercía la misma ocupación, entre otras, para las reinas de Navarra y de Castilla ${ }^{35}$.

\section{LOS COFRADES}

Las listas de asistentes a la reunión vienen a completar los conocimientos que teníamos sobre la aljama de la ciudad de Toledo. En primer lugar, podemos comprobar que la jerarquía judicial, que incluía a algunas de las principales familias mudéjares de la ciudad, se mantiene durante estos años respecto al siglo XIV, y enlaza con las personas que conocemos para el periodo más avanzado del siglo XV. No es de extrañar que aparezcan, pues, las familias al-Mawwāq, al-Šarqī, Šarafī, etc., entre los personajes destacados.

Éstas estaba presididas por las autoridades principales de la aljama: el alcalde mayor de los moros de la ciudad, cadíes y alfaquíes, si los había, o si no, por los alfaquíes o imames de las mezquitas. En las actas de 1404 aparece un listado completo de asistentes ordenados por rango jerárquico dentro de la aljama, encabezada por dos cadíes: Abū 'Abd Allāh Muḥammad ibn Yūsuf al-Qaysīi ${ }^{36}$ y Abū 1- Abbās

${ }^{35}$ ECHEVARRÍA, Ana y MAYOR, Rafael, "Las actas de reunión", f. 4v, f. 8v, 10v. Dice de Šamsī "que fue la esposa de $a l-G l b$ ". Se trata de una comadrona toledana que atiende a la reina Leonor de Trastámara en Navarra en el parto de su hijo Luis. GARCÍA-ARENAL, Mercedes y LEROY, Béatrice, Moros y judios en Navarra en la Baja Edad Media, Madrid, 1984, p. 32; MOLÉNAT, JeanPierre, "Privilégiées ou poursuivies: quatre sages-femmes musulmanes dans la Castille du XV siècle", en Identidades marginales, ed. C. de la Puente, EOBA XIII, Madrid, 2003, 415-416. El alfaquí debe ser este pues es el único Yuçaf mencionado en la cofradía toledana que ostenta este puesto. Fátima, comadrona de la reina Catalina de Lancaster, mujer de maestre 'Abd Allah -seguramente identificable con maestre 'Abd Allah Caracacho, que aparece repetidas veces en la documentación, o el maestre 'Abd Allah b. Sakir al-Awami (f. 6r) y madre de 'Abd Allah al-Sarqi (f. 5r), y de Haxa, que desempeñó la misma función después que ella.

${ }^{36}$ Es el mismo Muhammad b. Yūsuf al-Qaysī que suscribe la reunión del año 1403. Será nombrado alcalde mayor de las aljamas de moros desde 1408. Ver MOLÉNAT, Jean-Pierre, "Les Musulmans de Tolède aux $\mathrm{XIV}^{\mathrm{e}}$ et $\mathrm{XV}^{\mathrm{e}}$ siècles", en Les Espagnes médiévales. Aspects économiques et sociaux. Mélanges offerts à Jean Gautier-Dalché, Niza, 1983, 175-190: 176; idem, "L'élite mudéjare de Tolède aux XIVe et XV $\mathrm{XV}^{\mathrm{e}}$ siècle", en Liber largitorius. Études d'histoire médiévale offertes à Pierre Toubert, ed. D. Barthélemy et J.-M. Martin, Ginebra, 563-577: 572; idem, "Communautés musulmanes de Castille et du Portugal. Les cas de Tolède et de Lisbonne", en L'expansion occidentale (XIe - XVe siècles) Formes et conséquences. XXXIIIe Congrès de la SHMES, Madrid, 2002, 215-227, p. 226. También ECHEVARRÍA, Ana, "De cadí a alcalde mayor. La elite judicial mudéjar en el siglo XV", Al-Qantara XXIV (2003), 139-168 y 273-289, en concreto 149-150. 
Ahmad al-Mawwāa ${ }^{37}$, seguidos del alfaquí e imam Aḥmad al-Lajmī al-Šarafî̀ ${ }^{38}$. Las mismas personas presidirán la lista de la reunión de $1410^{39}$. En 1409 todavía se hace referencia a que hay dos jueces y un alfaquí, mientras que en 1410 sólo se dice un juez y un alfaquí, a pesar de que en el listado siguen apareciendo dos ${ }^{40}$. Parece que los cargos se trasmiten principalmente dentro de estas tres familias toledanas, dos de las cuales desempeñaron también la alcaldía mayor de las aljamas de todo el reino.

Otros personajes documentados que figuran en los listados son: Muhammad $b$. 'Alī al-Rūndīin ${ }^{41}$, posiblemente descendiente del primer alcalde mayor de la aljama de Toledo que tenemos documentado; el carpintero Muhammad al-Naŷȳâar ${ }^{22}$ y el herrero maestre 'Aziz al-Haddād ${ }^{43}$.

La familia de albañiles de los Carcacho, Caracacho o Carcachón es otra de las documentadas en la ciudad, concretamente varios de sus miembros aparecen en es-

${ }^{37}$ Sobre la familia al-Mawwāq (o Almaguaque en castellano), MOLÉNAT, Jean Pierre, "L'élite mudéjare", pp. 568-569; en 570 habla del padre, Aḥmad, y MOLÉNAT, Jean Pierre, "Les musulmans de Tolède", p. 187, aunque no tiene registrado a este personaje en concreto. Ahmmad al-Mawwāq es el padre de Abrahem, y quizá de 'Abd Allāh, MOLÉNAT, Jean Pierre, "Les musulmans dans l'espace urbain tolédan aux XIV et $\mathrm{XV}^{\mathrm{e}}$ siècles", en Minorités et marginaux en Espagne et dans le midi de la France (VII - XVIII ${ }^{e}$ siècles), Actes du Colloque de Pau, 27-29 mai 1984, Paris, 1986, 129-141: 134.

${ }^{38}$ Sobre los Xarafí de fines del XIV, MOLÉNAT, Jean Pierre, "Les musulmans dans l'espace urbain", 135. Este alfaquí está ya mencionado vendiendo una propiedad en 1395, casado con Sohra. MOLÉNAT, Jean Pierre, "Los Xarafî", p. 767. Otros Xarafíes en Molénat, "Les Musulmans de Tolède", 177. Quizá la misma doña Zuhra que aparece en el doc. 11, mencionada en MOLÉNAT, Jean Pierre, "Une famille de l'elite mudéjare de la Couronne de Castille: les Xarafi de Tolède et Alcalá de Henares", en Mélanges Louis Cardaillac. Études réunies et préfacées par Abdeljelil Temimi, Zaghouan, 1995, vol. 2, 765-772: 767. Los nombres de los miembros de la familia Xarafí, en MOLÉNAT, Jean Pierre, "Communautés", p. 226. Uno de sus descendientes, Ibrahim al-Lajmī Šarafī, firma como alfaquí en un pleito elevado en 1501 a la Chancilleria de Valladolid, VILLANUEVA, Olatz y ARAUS, Luis, "La identidad musulmana de los mudéjares de la Cuenca del Duero a finales de la Edad Media. Aportaciones desde la aljama de Burgos", Espacio, Tiempo y Forma, Serie III, H. ${ }^{a}$ Medieval 27 (2014) 525-546: 530

${ }^{39}$ La única diferencia es que al-Šarafì aparece designado ya con su kunya de Abu l- Abbas.

${ }^{40}$ ECHEVARRÍA, Ana y MAYOR, Rafael, "Las actas de reunión”, f. 5v, 8v.

${ }^{41}$ Posiblemente es el mismo Mahomad el Rondí casado con Habibo y que tiene casas en la ciudad en 1416. MOLÉNAT, Jean Pierre, "Les musulmans de Tolède", 186. AHN Clero, carp. 2966/13 y 2967/4. Aparece como Abū 'Abd Allāh Muhammad al-Rūndī en el doc. 13-14 (reunión de 1410), alquilando la tienda de la mezquita, y como 'Abd Allah Muhammad b. 'Abd Allah al-Rundi en el doc. 11 (reunión de 1411). Sobre el Rondí, MOLÉNAT, Jean Pierre, "Alcaldes et alcaldes mayores de moros de Castille au XVe siècle", en Regards sur al-Andalus (VIIIe-XVe siècle), ed. F. Géal, Madrid, 2006, 147-168 y ECHEVARRIA, Ana, "De cadí a alcalde mayor", 148. Otra Habibo, hija suya. MOLÉNAT, Jean Pierre, "Les musulmans dans l'espace urbain”, 132, 135, notas 16 y 19.

${ }^{42}$ Puede ser de una dinastía de carpinteros que alternan estos dos nombres, uno de los cuales era procurador de Don Diego Gómez en 1369. Cit. MOLÉNAT, Jean Pierre, "Les musulmans de Tolède", 178. La mezquita está al lado de un Corral de D. Diego.

${ }^{43}$ Más adelante su hijo Ahmad b. Muhammad al-Nayyar aparece como prioste y contable/repartidor de la cofradía. ECHEVARRÍA, Ana y MAYOR, Rafael, "Las actas de reunión", f. 10v. 
tas reuniones: mu'allim 'Abd Allāh Qrqyua en la reunión de $1402^{44}$ junto a los que presumiblemente serían sus sobrinos, Aḥmad b. 'Alī Qarqaŷuh y Muhammad b. 'Alī Qarqaŷuh ${ }^{45}$, quienes junto a su hermano 'Abd Allāh b. 'Alī Qarqaŷuh, aparecen pronto también como maestres, mostrando cómo ascienden de categoría social los miembros de las familias del gremio de la construcción, y su continuidad en la cofradía durante varias generaciones ${ }^{46}$.

Una vez más, encontramos entre los asistentes nisbas geográficos utilizados en castellano ya como apodos o apellidos que hacen referencia a otras poblaciones castellanas con aljamas conocidas (Burgos, Cuenca, Valladolid, Talavera, Ocaña), que podrían ser transeúntes en Toledo, o haberse afincado allí por motivaciones diversas. El que no se trate de ciudades granadinas y por tanto no sean emigrados de frontera hace pensar que, efectivamente, estos mudéjares pudieran provenir directamente o en una generación cercana, de dichos lugares.

\section{LIMOSNAS Y OTROS ASUNTOS ECONÓMICOS}

En las reuniones también se elegía a los contadores que se harían cargo de las limosnas de la comunidad y de la gestión de los bienes habices de la mezquita. Las necesidades de la aljama podían subvencionarse con recurso a distintas medidas. Por una parte, estaban las donaciones piadosas o bienes habices de las mezquitas. En Tornerías, se trata sobre todo del alquiler de la tienda que pertenece a la mezquita, que estaba situada en los bajos de la sala de oración, y que constituía un bien habiz de la misma ${ }^{47}$. De este alquiler se sacaba una cantidad para contribuir a sus gastos de mantenimiento, práctica que ya conocemos en otros lugares, como Ávila ${ }^{48}$. También podían establecerse otras formas de pago extraordinarias para subvencionar los gastos de reparación y culto.

\footnotetext{
${ }^{44}$ Maestre 'Abd Allah Caracacho, albañil, situado en la lista de 1404 en el décimo lugar, poco después de las autoridades, bien por ser uno de los viejos de la aljama o una de las personas de más relevancia entre los cofrades, pues se encuentra en prácticamente todas las reuniones. ECHEVARRÍA, Ana y MAYOR, Rafael, "Las actas de reunión", f. 2r, 3r, 4r, 5r, 6r, 7v, 9v, 10v. Ver MOLÉNAT, Jean-Pierre, "Les mudéjars de Tolède: professions et localisations urbaines", en Actas del VI Simposio Internacional de Mudejarismo, Teruel, 1995, 429-435:431.

${ }^{45}$ Los dos asisten a las reuniones de 1402, 1404 y 1405 junto a su tío. Véase nota anterior.

${ }^{46}$ Aquí disentimos de la opinión de BARROS, F. L. de, "Categorías sociais nas comunidades mudéjares ibéricas (séculos XIV-XV)", en Categorias sociais e mobilidade urbana na Baixa Idade Média. Entre o Islão e a Cristandade, Lisboa, 2012, pp. 35-60, p. 45, en el que opina que el tratamiento de maestre que observamos en estas personas no se refiere necesariamente al desempeño de un grado más elevado en la jerarquía del oficio.

${ }^{47}$ ECHEVARRÍA, Ana y MAYOR, Rafael, "Las actas de reunión”, f. 7r.

${ }^{48}$ ECHEVARRIA, Ana, "Los mudéjares al norte del Sistema Central: nuevas aportaciones sobre la aljama de Ávila", en Minorías étnico-religiosas na Península Ibérica (Periodo Medieval e Moderno). Lisboa, 2008, 291-306: 295-296.
} 
La cuestión de la limosna (șadaqa) es el tema omnipresente, objeto de la mayor parte del espacio de todas las actas conservadas, que incluyen en algunos casos las cuentas derivadas de la colecta ${ }^{49}$. El significado original de șadaqa como limosna voluntaria es aquí de especial importancia. A pesar de que muchos trabajos sobre impuestos no diferencian entre los significados de zakāt y șadaqa, intercambiables en muchas fuentes legales islámicas, el carácter voluntario, supererrogatorio y expiatorio de la segunda palabra viene ya especificado en el Corán, mientras que zakāt sería aplicada a las limosnas obligatorias. Al contrario que el zakāt, cuyo valor y naturaleza es fijado por ley, la șadaqa puede ser estipulada libremente, lo que le confiere una especial flexibilidad. Sus primeros beneficiarios debían ser los parientes y vecinos más pobres, pero también la mezquita, cuyas autoridades eran las capacitadas para recibirla, y esta doble vertiente de solidaridad horizontal junto con el mantenimiento de los lugares de culto sería la cultivada por los mudéjares ${ }^{50}$. En los documentos que nos ocupan, este tipo de limosna recibe el nombre de "limosna

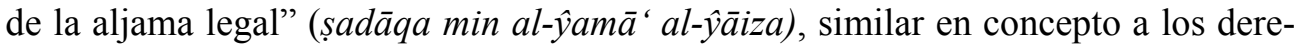
chos existentes en Aragón con la denominación de "mesquitas", percibidos por los propios funcionarios de la aljama ${ }^{51}$.

Las cantidades entregadas en este concepto no son excesivas -uno o dos meticales-, y sin duda estaban calculadas para atender a las necesidades, pero no ser una carga especialmente grave para los mudéjares que las pagaban, en su mayoría profesionales de economía saneada, pero no ricos. Las cantidades se miden en meticales, probablemente una equivalencia con el maravedí de plata, moneda de cuenta de la época, o en coronados, referencia a las efigies reales que decoraban el reverso de las piezas de Juan II. La transferencia de las cantidades a la forma de cuenta árabe probablemente mantiene la tradición de prácticas anteriores, en las que el metical aludía al metal no acuñado, o bien a la moneda en circulación para el pa-

${ }^{49} \mathrm{Se}$ trata de un listado de nombres con las cantidades correspondientes pagadas por cada cabeza de familia, según su situación personal. ECHEVARRÍA, Ana y MAYOR, Rafael, "Las actas de reunión", f. $11 \mathrm{r}$.

${ }^{50}$ El campo léxico de șadaqa es más amplio, por lo que no es extraño encontrar este término englobando a los demás. Algunos juristas plantean la diferencia en cuanto que zakāt es aquello que debe darse a las autoridades (de las propiedades personales, sobre todo oro y plata), mientras que șadaqa se refiere a aquello que las autoridades deben tomar (de las cosechas y ganado). Por ello, para evitar ambigüedades, el término șadaqa suele utilizarse con una segunda parte que describe su uso concreto, como vermos a continuación. La motivación piadosa en la concesión de la limosna, justifica su poder salvífico. En algunas fuentes también presenta un matiz de "limosna permanente", extendible a los bienes habices, cuyo contenido resulta también interesante en este contexto. Si la limosna se daba en viernes o durante el Ramadán, poseía aún más valor. "Sadāka", T. H. Weir y A. Zysow, Encyclopedia of Islam, VIII, pp. 709-716.

${ }^{51}$ ECHEVARRÍA, Ana y MAYOR, Rafael, "Las actas de reunión”, f. 4 r. Es posible que este impuesto pueda identificarse también en los tratados de legislación mudéjares y moriscos en el denominado "azaque de la alfitra", que se pagaba el día de la fiesta de la Ruptura del Ayuno. ABBOUD-HAGGAR, Soha, (trad. y ed.), El tratado jurídico de al-Tafrī' de Ibn al-Ğalläb. Manuscrito aljamiado de Almonacid de la Sierra, Zaragoza, 1999, vol. II, 144-146. 
go del azaque desde época de 'Abd al-Rahman III, retomada por los almohades como unidad de cuenta para el pago del diezmo ${ }^{52}$. El metical podía utilizarse también como medida de peso, con un equivalente a unos 4,66 g. de oro todavía a principios del siglo XVI, pero es evidente que los pagos continuos a la aljama no podían realizarse en ese metal $^{53}$.

Sin embargo, otro grupo de contribuyentes pagaba sumas superiores, en este caso los privilegiados (designados como "excusados"). Los mismos documentos se encargan de definir su lugar en la sociedad mudéjar: "son los jueces, alfaquí, imam, y los ancianos que tienen de setenta años en adelante" $"{ }^{4}$. Todos los años, los miembros de la cofradía pagaban dos meticales en concepto de limosna mientras que los escuchados/excusados pagarían cinco. Hay algunas excepciones, como en 1410, en que la necesidad de liquidez que debió padecer la aljama hizo que todos pagaran 3 meticales; otro listado sin fecha en el que todos pagan 6 meticales, y en 1414, año en el que los excusados llegaron a pagar 10 meticales $^{55}$. En cuanto a cómo debía distribuirse la șadaqa, el Tafrī' de Ibn al-Ŷallāb, que recoge las instrucciones dadas en la azora "del Arrepentimiento", sus frutos debían distribuirse entre los pobres, sus limosneros, o los viajeros; utilizarse para el rescate de cautivos por las aljamas; para la mezquita, para construir un puente, o para amortajar a los muertos ${ }^{56}$.

Otro de los temas recurrentes en las actas es el compromiso por parte de algún miembro de la comunidad de pagar las caloñas durante el año en curso, aparte de la limosna habitual, explicándose que dichas caloñas son "según las costumbres". La definición técnica de la caloña como indemnización o composición en metálico pagada por una herida $u$ homicidio se fue extendiendo durante la Edad Media al pago de cualquier indemnización por agresión o violación de la paz del rey en un lugar público, fuera éste el mercado, los caminos, las asambleas públicas, etc ${ }^{57}$. Este tipo

${ }^{52}$ PELLICER Y BRU, José, Al-Andalus. Las fuentes y la numismática, Barcelona, 1988, 37-39. Es imposible contrastar los valores de la moneda en el siglo X con los que tendría en el XV, y la palabra metical o mizcal se utilizaba tanto para la moneda de oro como para su equivalencia en plata /72 granos de oro o 24 quirates, equiparados a dos dirhames andalusíes, pero equivalente a 4,66 gr., o a un séptimo de la onza romana. VIGUERA MOLINS, María Jesús, "Partición de herencia", p. 130 hace una equivalencia directa entre los meticales y los maravedíes como moneda de vellón en el siglo XV.

${ }^{53}$ PELLICER Y BRU, José, "Noticias numismáticas de la Duquesa de Medina Sidonia", Gaceta Numismática 155 (2004) 29-37, esp. 31.

${ }^{54}$ En los documentos de 1409 y de 1410 se incluyen además los nombre de los mu allim (maestres de oficios) que son también escuchados.

${ }^{55}$ ECHEVARRÍA, Ana y MAYOR, Rafael, "Las actas de reunión”, f. 7r, 9v.

${ }^{56}$ ABBOUD-HAGGAR, Soha, El tratado jurídico, vol. II, 147-149.

${ }^{57}$ Aquí se utiliza en castellano, transcrita. GARCÍA DE VALDEAVELLANO, Luis, Historia de las instituciones, Madrid, 1982, 324, 327, 333, 440-441, 602-603. La aplicación de la caloña y su pago por la familia del ofensor queda reflejada en los fueros romanceados, como el de Palencia, en estos términos: "[Del que moro de paz firiere]. Ley II. Todo omne que moro de paz firiere o matare, peche por el commo por christiano; si moro de paz, christiano matare o firiere, por la ferida peche la calonna [a fuero de] Plazencia; por el matamiento, metanlo en mano de los parientes del quereloso que faga[n] del o de la calonna lo que quisieren." J. Majada Neila, Fuero de Plasencia, art. 63. F. Corriente, A 
de multa era también aplicada en derecho islámico (ta 'qal= pagar la caloña; al'aqila $=$ los parientes del homicida que debían hacerse cargo de los pagos) ${ }^{58}$, con una estipulación de plazos de hasta tres años en el caso de que la suma debiera satisfacerla la familia. Si el homicidio o agresión se había cometido sin premeditación era la parentela la encargada de hacer frente a los pagos -nunca las mujeres y los niños-, pero si había sido a sabiendas, sería el criminal quien se hiciese cargo de las indemnizaciones $^{59}$. Las cifras varían entre 16 y 55 meticales según los documentos, y no parece haber una constante en cuanto a quiénes realizan el pago. Parece que, efectivamente, se trataba de hacer frente a multas impuestas en castigo a un crimen determinado, que podían ser levantadas por orden del juez: "a condición de que le dé orden del juez para poder /librarse/ el que cae en /caloña/ en su momento /sin exceso" ${ }^{\circ}$. Cabría la posibilidad de que se hubieran convertido en un impuesto más o menos estable que tuviera que pagarse en algún concepto.

\begin{tabular}{|c|c|c|}
\hline Fecha & Nombre & Cantidad \\
\hline 1402 & 'Abd Allah b. Sa ${ }^{e} \overline{1} d$ al-Ḥaddād & 40 meticales \\
\hline 1403 & 'Abd Allāh Sa'īd & 16 \\
\hline 1405 & Muḥammad b. ‘Alī al-K.fāḥ̄ & 20 \\
\hline 1408 & 'Alī b. al-Șaffār & 20 \\
\hline 1409 & 'Alī al-M.j.lāf & 50 \\
\hline 1410 & $\begin{array}{c}\text { Abrāhīm b. al-Lūzīrāq } \\
\text { Maestre Sa`î̀d al-Kzīz de h.rīr } \\
\text { Maestre Abrāhīm Manșur } \\
\text { Yūsuf b. 'Alī Bono }\end{array}$ & 55 \\
\hline Después de 1410 & & 60 \\
\hline 1414 & Maestre Sulaymān de Burgos & 110 \\
\hline s.f. & Muhammad b. Ibrāhīm Alvaro de Ocaña & 35 \\
\hline s.f. (doc. 6) & Yūsuf b. al-M.h.min & 15 \\
\hline
\end{tabular}

Finalmente, las reuniones de la cofradía se refieren en un caso al magram, pero la falta de contexto hace difícil la interpretación de este término: "Obtuvieron de parte de los compañeros doce meticales. Y ordenó el juez que les contaran para el tributo" ${ }^{\circ}$. La palabra magram tiene este significado, pero es difícil saber si el tributo al que se refiere es un impuesto establecido, como el almagram que según Torró, sería una carga derivada del diezmo genérico ('ušr que se aplicaba preferentemente a la

Dictionary of Andalusi Arabic, Leiden, 1997, p. 440, define el árabe qalunyah como "una multa por difamar a alguien", cit. ECHEVARRÍA, Ana y MAYOR, Rafael, "Las actas de reunión", 277, nota 107.

${ }^{58}$ ABBOUD-HAGGAR, Soha, El tratado jurídico, vol. I, 190.

${ }^{59}$ En el "Libro de las sangres". ABBOUD-HAGGAR, Soha, El tratado jurídico, vol. II, 552-556.

${ }^{60}$ ECHEVARRÍA, Ana y MAYOR, Rafael, "Las actas de reunión", f. 9 r.

${ }^{61}$ ECHEVARRÍA, Ana y MAYOR, Rafael, "Las actas de reunión", f. 6 v. 
producción de las tierras irrigadas, y quizá podría asimilarse al diezmo eclesiástico del que hemos hablado previamente ${ }^{62}$.

La distribución de comida era considerada, dentro de la práctica de la hospitalidad, como una acción meritoria desde el punto de vista espiritual. A su vez, la comida que se recibía era considerada también como fuente de bendición. A nivel de las reuniones de los cofrades, era fundamental determinar quiénes eran los encargados de organizar las comidas y correr con los gastos. Esta función, que se encomendaba durante un periodo de cuatro meses, debería dar una indicación sobre el nivel de influencia y la riqueza del organizador suficiente para afrontar estos gastos y proporcionar un lugar -denominado "casa", pero que evidentemente debía poseer una sala o al menos un patio en el que cupieran todos los miembros presentes- para la reunión. De ahí que en 1402 se eligiera una vivienda cristiana, sin duda un palacio de los que abundaban en la ciudad, cedida por una señora mencionada solo como doña Juana, imposible de identificar por ahora ${ }^{63}$.

El banquete fraternal de los cofrades era también primordial entre las cofradías cristianas, en el día de la festividad de su patrón ${ }^{64}$. En el caso de la cofradía mudéjar, y al contrario que en las sufíes, en las que se aprovechaba el mawlid del Profeta o las fiestas del Sacrificio o del final del Ramadán ${ }^{65}$, las comidas se celebraban en domingo -en vez de en viernes-, probablemente porque era más sencillo encuadrarlas dentro del calendario laboral, condicionado por las prescripciones y fiestas cristianas. Tal como menciona el texto, se trata del día "en el que no trabajan ni los cristianos ni los musulmanes" ${ }^{\circ 6}$. Al banquete deben asistir todos los cofrades, y está minuciosamente regulado, hasta el punto de convertirse en un acto ritual, y de convivencia entre los hermanos. Se penaliza la introducción en la comida de gente ajena a la hermandad, y se excusa de los gastos ocasionados a los miembros pobres de la cofradía.

\section{CONCLUSIONES}

Nos encontramos ante una documentación fundamental para ampliar nuestros conocimientos en dos campos principales: la diglosia o bilingüismo de los musulmanes castellanos en un periodo tan tardío como el siglo XV, en el que hasta hace poco se pensaba que ya no utilizaban normalmente el árabe en la vida cotidiana, y el de la

${ }^{62}$ TORRÓ, Josep, "Del almagram a las particiones de frutos. Las cargas agrarias en las aljamas musulmanas del Reino de Valencia", en Los tributos de la tierra: fiscalidad y agricultura en España (siglos XII-XX), ed. R. Vallejo y A. Furió, Valencia, 2008, 175-212: 178.

${ }^{63}$ ECHEVARRÍA, Ana y MAYOR, Rafael, "Las actas de reunión", f. 3r.

${ }^{64}$ Sobre banquetes similares en una cofradía toledana cristiana contemporánea, la de San Pedro, MOLÉNAT, Jean-Pierre, "Menus des pauvres", 316-317.

${ }^{65}$ RODRÍGUEZ-MAÑAS, Francisco, "Charity and Deceit: The Practice of the iț'ām al-ța'am in Moroccan Sufism”, Studia Islamica 91 (2000) 59-90: 62.

${ }^{66}$ ECHEVARRÍA, Ana y MAYOR, Rafael, "Las actas de reunión”, f. 9v. 
religiosidad de la minoría musulmana en Castilla en un momento en el que las escasas presiones por parte de las autoridades cristianas aún hacían posible el desarrollo normal de las prácticas religiosas en el contexto de la vida urbana. Las actas de la cofradía toledana demuestran que el árabe andalusí seguía siendo utilizado, al menos por parte de une elite letrada mudéjar. Y la existencia de una cofradía, con todo lo que ello conlleva en cuanto a la implicación de los musulmanes de a pie en el funcionamiento de sus instituciones religiosas, plantea nuevos retos en la definición de la religiosidad bajomedieval musulmana en al-Andalus y sus antiguos territorios, es decir, en la parte ocupada por Granada, pero también en las zonas en las que los musulmanes eran minoría, aunque no desligada de los territorios del Islam. 